\title{
Prevalence of Renal Vascular Variations in Patients Subjected to Contrast CT Abdomen
}

\author{
Shivani Agarwal ${ }^{1}$, Senthil Kumar Aiyappan ${ }^{2}$, Anitha Christina Mathuram ${ }^{3}$, Nair Harikrishnan Raveendran \\ Valsala4, Vinayagam Shanmugam ${ }^{5}$ \\ ${ }^{1}$ Junior Resident, Department of Radiodiagnosis, ${ }^{2}$ Professor, Department of Radiodiagnosis, ${ }^{3}$ Junior Resident, Department \\ of Radiodiagnosis, ${ }^{4}$ Junior Resident, Department of Radiodiagnosis, ${ }^{5}$ Professor and Head of the Department, Department of \\ Radiodiagnosis, SRM Medical College Hospital and Research Centre, Kattankulathur, Kanchipuram, Tamilnadu-603203, India
}

Corresponding author: Senthil Kumar Aiyappan, Professor, Department of Radiology, Srm Medical College Hospital and Research Centre, Kattankulathur, Kanchipuram, Tamilnadu-603203, India

DOI: http://dx.doi.org/10.21276/ijcmsr.2019.4.2.26

How to cite this article: Shivani Agarwal, Senthil Kumar Aiyappan, Anitha Christina Mathuram, Nair Harikrishnan Raveendran Valsala, Vinayagam Shanmugam. Prevalence of renal vascular variations in patients subjected to contrast CT abdomen. International Journal of Contemporary Medicine Surgery and Radiology. 2019;4(2):B114B119.

\section{A B S T R A C T}

Introduction: To determine the prevalence of renal artery and renal vein variations in the patients subjected to contrast CT abdomen and to assess the gender specific variations in renal artery and renal vein.

Material and methods: The study was conducted in the department of Radiodiagnosis, SRM Medical College, Kattankulathur from March 2017 to August 2018. A total of 223 patients who were subjected to MDCT contrast abdomen study for various complaints were evaluated for the renal vascular variations. The study was done in two phases arterial and venous with field of view from the dome of diaphragm to the iliac crest. The axial images obtained were post-processed by MPR, MIP and VR techniques.

Results: Renal vascular variants are highly variable as observed in the previous studies. In our study, the most common renal artery variation was accessory renal artery and most common renal vein variation was multiple renal veins. No statistically significant association between gender and Renal artery, Renal vein or main renal artery lumen size was observed. Maximum renal arteries both on right and left side were seen arising at the level of L1.

Conclusions: MDCT is ideal for imaging. RA and RV variations including the number and course. Accessory renal artery is the most frequently observed variation in renal arteries and multiple renal vein is the most common variation of right renal vein. Retroaortic left renal vein was the most common variation observed on left side. Between gender and RA or RV no statistically significant association was demonstrated.

Keywords: Renal Vascular Variations, Contrast CT Abdomen

\section{INTRODUCTION}

MDCT Angiography is an excellent non invasive modality to analyse the renal vascular anatomy and its variations. Knowledge of the renal vascular variation is important prior to laparoscopic surgeries or partial nephrectomy in order to prevent post surgical complications. The awareness of this pre operative information is also important prior to many other surgical and non invasive procedures. Many renal artery variations are observed like accessory renal arteries, prehilar branching, multiple renal arteries. Most frequent renal vein variations analysed are multiple renal vein, late confluence, retro-aortic and circum-aortic renal veins. The distribution of these renal variations and the main renal artery lumen size with respect to the gender was studied. The knowledge of the orthogonal diameter of the renal artery is important prior to the surgery as anastomosis is difficult in smaller lumen size arteries. There have been very few articles in the literature describing about the relation in between gender and renal vascular variations.

Analysis of renal vascular variations is important while planning many surgical procedures like partial nephrectomy, kidney transplantation, in UPJ stenosis pyeloplasty. ${ }^{1,2,3}$ These variations can lead to significant surgical complications or even life-threatening events if unrecognised. The correct renal vascular anatomy can help chose the right surgical technique. Prior to partial nephrectomy surgeries, knowledge about the vascular anatomy is necessary. Technical measure like reducing the warm ischemia time helps in improving partial nephrectomy functional results. ${ }^{4,5}$ For better renal function in the immediate post-operative phase the key technique used is clamping the segmental artery, instead of the main artery. The development of VR images and MIP imaging studies allows greater accuracy in the clamping of the segmental artery. ${ }^{6}$ Earlier knowledge of the vascular anatomy helps us decide the surgical approach as they can make the laparoscopic procedures difficult and reduce the 
success rate. ${ }^{6}$

\section{MATERIALS AND METHODS}

The study was conducted in the department of Radiodiagnosis, SRM Medical College, Kattankulathur from March 2017 to August 2018. A total of 223 patients who were subjected to MDCT contrast abdomen study for various complaints were evaluated for the renal vascular variations. Randomized sampling technique used in the study. Pregnant female, patients below 18 years, patients with impaired renal function and post renal transplant patients excluded from the study. The equipment used was 128 MDCTGE Model: Optima 660 scanner and contrast used was non-ionic low osmolar contrast. The ethical committee approved the study protocol. Collimation of 1-3 mm was utilized with pitch of up to 2 for adequate coverage. IV cannula of 18/20 gauge was inserted into the cubital vein, through which contrast material of $70-80 \mathrm{ml}$ was injected at $4 \mathrm{ml} / \mathrm{sec}$ with the pressure injector followed by $20 \mathrm{ml}$ saline using the bolus tracking technique after which when the aorta HU reached 120, the scanning would start. The contrast material used was Omnipaque, Iohexol injection which is a low osmolar non iodinated contrast. To reduce radiation exposure Adaptive Iterative Dose Reduction (AIDR) reconstruction was use. The images obtained were reported by two experienced radiologists. The axial images obtained were post-processed by MPR, MIP and VR techniques. The images were send to the separate work station after which they were analysed and interpreted by two different radiologists. The Renal artery was evaluated for length, lumen diameter, presence of accessory renal arteries and gender variation.

The Renal vein was evaluated for length, lumen size, presence of multiple renal veins, circumaortic or retroaortic left renal vein, late venous confluence and gender variation. Associated findings included were length of kidney, renal artery calcifications renal artery origin level and associated renal and other abdominal findings. Ethical clearance was obtained from the Institutional human ethical committee. Informed consent was obtained from each study participant, after explaining the risks and benefits involved in the study and voluntary nature of the participation, in a language participant can understand. Confidentiality of the study participants was maintained throughout trial conduction and dissemination of the study results.

\section{STATISTICAL ANALYSIS}

Data was analyzed using the SPSS version 22 software. Descriptive statistics were reported as mean (SD) for continuous variables and frequency (percentage) for categorical variables. Pearson's Chi-square test was used to find association between two categorical variables. A p value< 0.05 was considered as statistically significant.

\section{RESULTS}

A total of 223 patients who came to Department of Radiology, SRM medical college hospital and research center for contrast abdomen MDCT for various complaints were included in the study. Out of total 223 patients, the age group included was 18 years and above. The youngest patient included in the study was 18 years of age and the oldest was 85 years old. The mean age of the study was 46.3 years. $39.46 \%$ were males and $60.54 \%$ were females. Around 74.4\% were Hindu, $19.28 \%$ were Christian and $6.28 \%$ were Muslim by religion.

According to the study the average renal artery length was $27.39 \pm 12.38 \mathrm{~mm}$ on right and $26.28 \pm 13.04 \mathrm{~mm}$ on left. The average renal artery lumen diameter on right was $5.03 \pm 1.30$ $\mathrm{mm}$ and on left $4.92 \pm 1.46 \mathrm{~mm}$. The average renal vein length on right was $22.28 \pm 10.84 \mathrm{~mm}$ and on left $59.74 \pm 20.64 \mathrm{~mm}$. The average lumen size of renal vein on right was $7.17 \pm 3.39$ $\mathrm{mm}$ and on left was $6.40 \pm 6.98 \mathrm{~mm}$.

The accessory renal artery variations were $29.1 \%$ out of which $16.4 \%$ on right and $20.5 \%$ on left. Out of all the variations, $11.8 \%$ was hilar, $7.7 \%$ upper polar, $4.09 \%$ lower polar, $18.85 \%$ prehilar and $1.64 \%$ multiple renal artery. The total distribution of renal artery variations (including prehilar branching and right and left accessory arteries) were $35.41 \%$ out of which $30.4 \%$ on right and $34.10 \%$ on left were seen. On right side, around 24 subjects had hilar (10.40\%), 9 had lower polar (3.90\%), 46 had pre-hilar (19.91\%), 12 had

\begin{tabular}{|c|c|c|c|}
\hline Lumen size & $\begin{array}{c}\text { Male } \\
(N=134)\end{array}$ & $\begin{array}{l}\text { Female } \\
(\mathrm{N}=88)\end{array}$ & $P$ value \\
\hline $1-3 \mathrm{~mm}$ & $3(2.22)$ & $4(4.54)$ & \multirow{3}{*}{0.40} \\
\hline $3-5 \mathrm{~mm}$ & $66(48.89)$ & $42(47.72)$ & \\
\hline$>5 \mathrm{~mm}$ & $66(48.89)$ & $42(47.72)$ & \\
\hline
\end{tabular}

Table-1: Gender wise distributions with lumen size on right side $(\mathrm{N}=223)$

\begin{tabular}{|l|c|c|c|}
\hline Lumen size & $\begin{array}{c}\text { Male } \\
(\mathbf{N}=\mathbf{1 3 4})\end{array}$ & $\begin{array}{c}\text { Female } \\
(\mathbf{N}=\mathbf{8 8})\end{array}$ & P value \\
\hline $1-3 \mathrm{~mm}$ & $5(3.70)$ & $7(7.95)$ & \multirow{2}{*}{0.21} \\
\hline $3-5 \mathrm{~mm}$ & $65(48.15)$ & $43(48.86)$ & \multirow{2}{*}{0.21} \\
\hline$>5 \mathrm{~mm}$ & $65(48.15)$ & $38(43.18)$ & \\
\cline { 1 - 3 } & &
\end{tabular}

Table-2: Gender wise distributions with lumen size on left side $(\mathrm{N}=223)$

\begin{tabular}{|l|c|c|}
\hline Right renal vein & $\begin{array}{c}\text { Males } \\
(\mathbf{n = 1 3 4 )}\end{array}$ & $\begin{array}{c}\text { Females } \\
(\mathbf{n}=\mathbf{8 9})\end{array}$ \\
\hline Retro aortic renal vein & 0 & 0 \\
\hline Circum aortic renal vein & 0 & 0 \\
\hline Double renal vein & $22(16.42)$ & $20(22.47)$ \\
\hline Late confluence of renal vein & $21(15.67)$ & $12(13.48)$ \\
\hline No Variation & $91(40.80)$ & $57(64.04)$ \\
\hline
\end{tabular}

Table-3: Distribution of right renalvein variation according to gender $(\mathrm{N}=223)$

\begin{tabular}{|l|c|c|}
\hline Left renal vein & $\begin{array}{c}\text { Males } \\
\text { (n=134) }\end{array}$ & $\begin{array}{c}\text { Females } \\
\text { (n=89) }\end{array}$ \\
\hline Retro aortic renal vein & $9(6.72)$ & $4(4.49)$ \\
\hline Circum aortic renal vein & $3(2.24)$ & $2(2.25)$ \\
\hline Double renal vein & $3(2.24)$ & $4(4.49)$ \\
\hline Late confluence of renal vein & 0 & 0 \\
\hline No Variation & $119(88.81)$ & $79(88.76)$ \\
\hline Table-4: Distribution of left renalvein variation according to \\
gender (N=223) \\
\hline
\end{tabular}


upper polar (5.19\%) and 2 had multiple renal artery (0.86\%). Maximum number of renal artery variations were seen on left side out of which 29 subjects had hilar (12\%), 10 had lower polar (4.09\%), 42 had pre-hilar (17.21\%), 19 had upper polar (7.78\%) and 4 had multiple renal artery (1.63\%). Each subject had multiple combinations of variants.

On right side, single accessory artery was seen in $16.5 \%$ patients, $2.2 \%$ double accessory artery. No patients had more than double accessory arteries. On left side, single accessory artery was seen in $19.2 \%$, double AA in $2.24 \%$ and triple accessory artery in $0.45 \%$ patients.

Maximum renal arteries both on right and left side were seen arising at the level of $\mathrm{L} 1$, with $66.3 \%$ on right side and $68.66 \%$ on left side. On right side, one MRA i.e $0.44 \%$ originated at the level of D11, 8 at D12 level (3.6\%), 55 at the level of L2 (24.65\%), 9 at L1-L2 level(4\%), 2 at L3 level (0.9\%). On the left side, 2 originated at D12 level (0.9\%), 56 at L2 level (24.1\%), 10 at L1-L2 level(4.48\%), 1 at L3 level (0.45\%).

On the basis of gender, among 134 males, 10.45\% had hilar variations of right renal artery, $2.99 \%$ had lower polar, $18.66 \%$ had pre-hilar, $3.73 \%$ had upper polar and $0.74 \%$ had multiple renal artery. Among 89 females, $8.99 \%$ had hilar variations of right renal artery, $11.24 \%$ had lower polar, $14.60 \%$ had prehilar, $6.75 \%$ had upper polar and $1.12 \%$ had multiple renal artery. Similarly for left renal artery among 134 males 6.72\% had hilar variations, 3.73\% had lower polar,11.19\% had prehilar, $7.46 \%$ had upper polar and $2.99 \%$ had multiple renal artery. And among 89 females $11.24 \%$ had hilar variation, $5.62 \%$ had lower polar, $17.98 \%$ had pre-hilar, $10.11 \%$ had upper polar and $1.12 \%$ had multiple renal artery variations. Out of 88 females, $38.12 \%$ had no variations, $11.21 \%$ had accessory renal artery and $11.21 \%$ had prehilar branching. Out of 134 males, $22.87 \%$ had no variations, $12.56 \%$ had accessory renal artery and $5.83 \%$ had prehilar branching. Prehilar branching was more in females compared to males. Accessory artery in males was almost equal to the females.

The distribution of lumen size with right renal artery variations (hilar, upper polar, lower polar) are as follows. Out of 38 subjects $2.63 \%$ of them are having lumen size $1-3 \mathrm{~mm}$, $55.25 \%$ are having lumen size $3-5 \mathrm{~mm}$ and $42.11 \%$ more than $5 \mathrm{~mm}$. The distribution of lumen size with left renal artery variations (hilar, upper polar, lower polar) are as follows. Out of 46 subjects $50 \%$ are having lumen size $3-5 \mathrm{~mm}$ and $50 \%$ more than $5 \mathrm{~mm}$. The mean lumen size of right main renal artery was $5.03+/-1.30 \mathrm{~mm}$ and left main renal artery was 4.92+/-1.46 mm.

The gender wise distributions with respect to lumen size on right side is as follows. Out of 223 participants, $2.22 \%$ of males and $4.54 \%$ of females are having lumen size $1-3 \mathrm{~mm}$, $48.89 \%$ of males and $47.72 \%$ of females are having lumen size $3-5 \mathrm{~mm}$ and $48.89 \%$ of males and $47.72 \%$ of females are having lumen size more than $5 \mathrm{~mm}$. There was no statistical association between them. $(\mathrm{p}=0.40)$ [Table 1 ].

The gender wise distributions with respect to lumen size on left side is as follows. Out of 223 participants, 3.70\% of males and $7.95 \%$ of females are having lumen size $1-3 \mathrm{~mm}$, $48.15 \%$ of males and $48.86 \%$ of females are having lumen size $3-5 \mathrm{~mm}$ and $48.15 \%$ of males and $43.18 \%$ of females are having lumen size more than $5 \mathrm{~mm}$. There was so statistical association between them. $(\mathrm{p}=0.21)$ [Table 2].

On the right side among 223 cases, 18.83\% had double renal vein, $14.81 \%$ had late confluence of renal vein and $148 \mathrm{had}$ no variations (66.36\%). On the left side, among 223 cases, $5.83 \%$ had retro aortic renal vein, $2.24 \%$ had circum aortic renal vein and $3.14 \%$ had late confluence of renal vein and 198 had no variations (88.8\%).

The total renal vein variations were $39.06 \%$ on right and $13.02 \%$ on left out of which around $5.41 \%$ of the study subjects had retro aortic renal vein, $2.08 \%$ had circum aortic renal vein, $17.21 \%$ had double renal vein and $13.33 \%$ had late confluence of renal vein

Among 134 males, 16.42\%\% had double renal vein, 15.67\% had late confluence of renal vein on right side respectively. Similarly among 89 females $22.47 \%$ had double renal vein, $13.48 \%$ had late confluence of renal vein on the right side. With respect to left renal vein, among 134 males, 6.72\% had retro aortic renal vein, $2.24 \%$ had circumaortic renal vein and $2.24 \%$ had double renal vein. Similarly among 89 females, $4.49 \%$ had retro aortic renal vein, $2.25 \%$ had circum aortic renal vein and $4.49 \%$ had late confluence of renal vein [Table 3,4]. There were no statistically significant correlation between renal vein variations among males and females.

\section{DISCUSSION}

This study conducted in SRM Medical College and Research Centre consisted of a total of 223 patients, a total of 446 kidneys. The mean age of the patient was 46.2 years. The age of the patients in this study varied from 18 to 85 years who were retrospectively reviewed for the renal vascular variations. The mean age in this study was comparatively lesser than the study conducted by Cinar et $\mathrm{al}^{1}$ 2016, which included the patients with a mean age of 56.4 years. Maximum number of participants were around 30 to 60 years of age. Only around $20 \%$ of the patients were less than 30 years of age.

In this study, the male participants were 134 (60.54\%) and female participants were $39.46 \%$. The male population was much more than the female population. All the patients came to SRM Medical College and Research Centre Radiology Department for various abdominal complaints for which abdomen CT was done. Out of 223 patients, 74\% were Hindus, $19.28 \%$ were Christian and 6.28\% were Muslim.

Two or more renal arteries with separate origin, the artery with the greatest diameter is considered as the main renal artery and the rest as accessory renal artery. The accessory renal artery can be further divided into hilar, upper polar and lower polar. ${ }^{8}$

Previously, accessory renal arteries prevalence was based on DSA and autopsy findings. In the literature, accessory renal arteries prevalence is given in between $9-76 \%$ range. In the postmortem studies it is given as $28-30 \% .{ }^{9,10}$ The prevalence of accessory renal arteries in our study was $29.10 \%$. This is a closer estimate to the study done by Sofia Sabouri et $\mathrm{al}^{11}(2011)$ in which the prevalence rate was $38.2 \%$ and also to the study done by Cinar et $\mathrm{al}^{8}$ (2016) which showed the prevalence rate of $31.3 \%$. Ozkan et $\mathrm{al}^{12}$ published a study with 855 participants, including the DSA examinations in which the accessory renal artery prevalence was $24 \%$ In the 
literature, prevalence of single renal artery is the maximum which is in accordance with this study. However, the study done by KumaresanMunnusamy et $\mathrm{al}^{13}(2016)$ published that out of 100 kidney donors $51 \%$ had variations which is more compared to this study.

In our study, more renal accessory arteries were seen on left side as compared to the right side with respective prevalence of $18.8 \%$ and $15.5 \%$ which was similar to the study done by $\mathrm{Cinar}$ et $\mathrm{al}^{8}(2016)$. However, previous studies done by UgurOzkan et $\mathrm{al}^{12}$ (2006), Holden et $\mathrm{al}^{14}(2005)$ showed that the accessory renal arteries were more on right side as compared to the left side. Few Indian studies done in the south India population were also published. Kumaresan Munnusamy et $\mathrm{al}^{13}$ (2016) study showed equal right and left renal artery variations i.e. $13 \%$ accessory renal artery was present on right and left each and $12 \%$ on right left both sides.

Prehilar branching of the main renal artery was given as $8 \%$ in the study done by Ozkan $\mathrm{U}^{12}(2006), 13.3 \%$ in an Indian study conducted by Sharmila Aristotle et al ${ }^{15}$ (2013) and $13 \%$ in the study by Kumaresan Munnusamy. ${ }^{13}$ In our study, the prevalence of prehilar branching of main renal artery was $18 \%$ (19.9\% on right side and $17.2 \%$ on left side, which was almost similar to the findings observed by Kawamoto et $\mathrm{al}^{60}$ which was $19 \%$ and Raman et $\mathrm{al}^{16} 21 \%$ in left renal arteries and $15 \%$ on right side. For suitable anastomosis and controlling the hemorrhage easily atleast $1.5-2 \mathrm{~cm}$ length of the main renal artery is required for the incision. Thus, knowledge of prehilar branching of the main renal artery is very important clinically. The prevalences observed for prehilar branching of main renal artery reported in the literature ranges in between $4.3 \%$ and $13 \%{ }^{17,18}$

Studies between renal vascular variations and gender is very limited in the literature. In our study, prehilar branching was slightly more in females as compared to the males, and accessory renal arteries were almost equal. However, no statistically significant difference was noted similarly to the study done by Cinar et al. ${ }^{8}$ However, the study published by KS satyapalet $\mathrm{al}^{16}$ observed that the first additional accessory renal arteries were observed more in males compared to females which was statistically significant.

The mean lumen size in this study was $7.17 \pm 3.39 \mathrm{~mm}$ on right side and $4.92 \pm 1.46 \mathrm{~mm}$ on left side. Mean diameter of right renal artery was $5.04 \pm 1.34$ in males and in females was $5.02 \pm 1.25$. Mean diameter of left renal artery was $5.11 \pm 1.44 \mathrm{~mm}$ in males and $4.64 \pm 1.42$ in females. There was no statistically significant variation seen in males and females. However, siginificant difference in the right and left mean lumen diameter of males and females was observed by Maria Mohiuddin et al. ${ }^{20}$

Renal vein anatomy even if it is complex is not a contraindication for laparoscopic surgery. ${ }^{66}$ However, variations such as circumaortic or retroaortic vein is necessary to analyze before the surgery to avoid RV incision. $\mathrm{RV}$ variation is also important to be known in the patients who will have IVC filters placed, or in RV catheterization for renin sampling. Studies done prior states that there might be relation between pelvic varicosis and retroaortic or circumaortic left renal vein. ${ }^{21,22}$ Increase in retroaortic left renal vein tension can lead to thrombosis, hematuria and hypertension. ${ }^{22}$

In postmortem and angiographic studies prevalence ofleft and right multiple renal veins are $1-2 \%, 11-28 \%$ and retroaortic vein $1-3 \% .{ }^{23}$ Studies with angiography and surgical findings observed leftcircumaortic renal vein prevalence was $1-2 \%{ }^{29}$ and in postmortem study was $2-17 \% .^{24}$

In our study, prevalence of circumaortic and retroaortic vein observed was $2 \%$ and $5.4 \%$ respectively. Study done by koc et $\mathrm{al}^{21}$ in 1120 patients analysed that $14.3 \%$ had multiple right renal vein, $5.5 \%$ circumaortic left renal vein and $4.6 \%$ had left retroaortic vein. Maximum variation on the right side is the multiple renal vein which is $18.8 \%$ and is similar to the previous study done by Cinar et al. ${ }^{36}$ On the left side left retroaortic vein is $5.8 \%$ which is most common. However, previous study done by Cinar et $\mathrm{al}^{8}$, Koc et $\mathrm{al}^{16}$ and Raman et $\mathrm{a}^{16}$ observed that the circumaortic vein prevalence was higher than the retroaortic vein.

Studies analyzing renal vascular anatomical variations observed no significant late renal vein confluence. Ozkan U et $\mathrm{al}^{12}$ did a study in which he observed that the prevalence of late confluence of right renal vein was $10 \%$ and on the left side was $17 \%$. In our study, the late confluence of renal vein on right side was $14.8 \%$ and on left side no late renal vein confluence was observed. The finding on the right side is much similar to the study done by Ozkan U et al. ${ }^{12}$ The study done by Cinar et $\mathrm{al}^{8}$ published late renal veins confluence on right side $4.1 \%$ and on the left side $3.2 \%$. Late renal vein confluence was not observed in most of the studies done previously describing about renal vascular variations anatomy. ${ }^{8}$

No significant gender variation was noted with respect to the renal vein variation similarly to the study done by Cinar et al. ${ }^{8}$ However, studies done by koc et $\mathrm{al}^{21}$ and kawamoto et $\mathrm{al}^{25}$ reported that multiple right renal vein variations were common in females. However, no other renal vein variation prevalence in relation to gender was reported.

During MDCT examinations, to reduce the radiation dose many approaches have been done while maintaining the image quality. Approaches like modulation of automatic tube current, increasing the pitch of helical scanning, reducing the tube voltage, reconstructive methods like iterative reconstruction were used. ${ }^{26,27,28}$ In our study, we incorporated the use of AIDR reconstructions and automatic modulation of tube current to reduce the patient radiation dose.

Thus to summarize, we came across very few studies describing about the association in between renal vascular variations and gender. In this study, accessory renal arteries were slightly more common in males than females, and prehilar branching was more common in females as compared to males. However, no statistically significant difference was made.

According to the lumen size, also no significant gender variation was observed in this study. Maximum renal vein variations seen were double renal vein on the right side, which is slightly more common in females. Retroaortic vein was more common on left side which was slightly more in males compared to the females. However, no significant variations were seen according to the gender. Late renal vein 
confluence prevalence was found similar in terms of gender. Hence, no statistically significant association was demonstrated in between renal vascular variations and gender in this study.

\section{Limitations}

The limitation of our study was lack of including patients with high creatinine and urea levels. Patient below 18 years old were not included in the study due to issues with consent. Renal artery branching pattern and veins draining into left renal vein variations were not included in the study. Findings with DSA or post surgery were not evaluated. No association of one variant with another was not analysed.

\section{CONCLUSION}

For the evaluation of renal vascular variations and anatomy MDCT is an admirable modality for imaging. RA and RV variations including the number and course can be easily analysed accurately with the help of MDCT angiographic study. Accessory renal artery is the most frequently observed variation in renal arteries and multiple renal vein is the most common variation of right renal vein. Retroaortic left renal vein was the most common variation observed on left side. Between gender and RA or RV no statistically significant association was demonstrated.

\section{REFERENCES}

1. Bruce A. Urban, Lloyd E. Ratner, Elliot K. Fishman. Three dimensional Volume-rendered CT Angiography of the Renal Arteries and Veins: Normal Anatomy, Variants, and Clinical Applications. Radio Graphics 2001; 21(2):373-386.

2. Julio A P, Francisco G T,Alejandro M T, Laura K F,Chawar H, Isaac D N. Angio CT assessment of anatomical variants in renalvasculature: its importance in the living donor. Insights Imaging 2013; 4 (1):199211.

3. Thompson RH, Lane BR, Lohse CM. Renal function after partial nephrectomy: effect of warm ischemia relative to quantity and quality of preserved kidney. Urology 2012;79 (5):356-60.

4. Nguyen MM, Gill IS. Halving ischemia time during laparoscopic partial nephrectomy. J Urol. 2008;179 (2):627-32.

5. Carlos Fernando de Mello Júnior, Severino Aires AraujoNeto, ArlindoMonteiro de Carvalho Junior,Rafael Batista Rebouças, Gustavo Ramalho Pessoa Negromonte, CarollyneDantas de Oliveira. Multidetector computed tomography angiography of the renal arteries: normal anatomy and its variations. Radiol Bras. 2016;49(3):190-195.

6. KokNFM, Dols LFC, Hunink MGM. Complex vascular anatomy in live kidney donation: imaging and consequences for clinical outcome. Transplantation 2008;85 (3):1760-5.

7. Galley RES, Keane TE. Embryology, anatomy, and surgical applications of the kidney and ureter. Surg Clin North Am. 2000; 80 (4):381-401.

8. C. C, Inar a, A. Türkvatanb. Prevalence of renal vascular variations: Evaluation with MDCT angiography. Diagnostic and Interventional Imaging 2016; 97: 891-
897

9. Khamanarong K, Prachaney P, Utraravichien A, TongUn T, Sripaoraya K. Anatomy of renal arterial supply. Clin Anat 2004;17 (6):334-6.

10. OllivierR, Boulmier D, Veillard D. Frequency and predictors of renal artery stenosis in patients with coronary artery disease. Cardiovasc Revasc Med 2009;10 (5):23.

11. Sofia Sabouri, Makhtoom Shanhnazi, Alireza Khatami, Behnam Ghiasvand. CT angiography in evaluation of live kidney donors. Pakistan Journal of Radiology 2011; 21(2): 63-66.

12. Ozkan U, Oğuzkurt L, Tercan F, Kizilkiliç O, Koç Z, Koca N. Renal arteryorigins and variations: angiographic evaluation of 855 consecutive patients. Diagn IntervRadiol. 2006;12(4):183-6.

13. Kumaresan Munnusamy, Sankaran Ponnusamy Kasirajan, Karthikeyan Gurusamy, Gunapriya Raghunath, Shilpakala Leshappa Bolshetty, Sudakshina Chakrabarti et al. Variations in Branching Pattern of Renal Artery in Kidney Donors Using Ct Angiography. Journal of Clinical and Diagnostic Research 2016; 10(3): AC01-AC03.

14. Holden A, Smith A, Dukes P, Pilmore H, Yasutomi M. Assessment of 100 live potential renal donors for laparoscopic nephrectomy with multi-detector row helical CT. Radiology 2005; 237 (1): 973-80.

15. Sharmila Aristotle, Sundarapandian, Christilda Felicia Mesenteric. Anatomical Study Of Variations In The Blood Supply Of Kidneys. Journal of Clinical and Diagnostic Research. 2013; 7(8): 1555-1557.

16. Raman Ss, Pojchamarnwiputh S, Muangsomboon K, Schulampg, Gritsch Ha, Lu Ds. Surgically Relevant Normal and Variantrenal Parenchymal And Vascular Anatomy In Preoperative 16-Mdct Evaluation Of Potential Laparoscopic Renal Donors. Ajram J Roentgenol 2007;188 (1):105-14.

17. Rydberg J, Kopecky KK, Tann M, et al. Evaluation of prospective living renal donors for laparoscopic nephrectomy with multisection CT: the marriage of minimally invasive imag-ing with minimally invasive surgery. Radiographics 2001;21 (6): 223-36.

18. Kim JK, Park SY, Kim HJ, et al. Living donor kidneys: useful-ness of multi-detector row CT for comprehensive evaluation. Radiology 2003;229 (1):869-76.

19. Satyapal KS, Haffejee AA, Singh B, Ramsaroop L, Robbs JV, Kalideen JM. Additional renal arteries: incidence and morphometry. SurgRadiolAnat 2001; 23 (2): 33-8.

20. Mohiuddin M, Manzoor A, Ali M, Hassan N. Analysis of renal artery morphometery in adults: A study conducted by using Multidetector computed Tomography Angiography. Pakistan Journal of Medical Sciences 2017;33(4):943-947.

21. Koc Z, Ulusan S, Oguzkurt L. Association of left renal vein variations and pelvic varices in abdominal MDCT. Eur Radiol 2007;17 (5):1267-74.

22. Karazincir S, Balci A, Görür S, Sumbas H, Kiper AN. Incidenceof the retroaortic left renal vein in patients with varicocele. J Ultrasound Med 2007;26 (2):601—4.

23. Pozniak MA, Balison DJ, Lee Jr FT, Tambeaux RH, 
Uehling DT, Moon TD. CT angiography of potential renal transplant donors. Radiographics 1998;18 (5):565-87.

24. Pollak R, Prusak Bf, MozesMf. Anatomic Abnormalities Of Cadaver Kidneys Procured For Purposes Of Transplantation. Amsurg1986;52 (1):233-5.

25. Kawamoto S, Lawler Lp, Fishman Ek. Evaluation Of The Renalvenous System On Late Arterial And Venous Phase Images Withmdct Angiography In Potential Living Laparoscopic Renal Donors.Ajr Am J Roentgenol 2005;184 (2):539-45.

26. Greffier J, Macri F, Larbi A. Dose reduction with iterative reconstruction: optimization of CT protocols in clinicalpractice. DiagnInterv Imaging 2015;96 (4):477-86.

27. Blum A, Gervaise A, Teixeira P. Iterative reconstruction: why,how and when? DiagnInterv Imaging 2015;96 (1):421-2.

28. Burrill J, Dabbagh Z, Gollub F, Hamady M. Multidetector computed tomographic angiography of the cardiovascular system. Postgraduate Medical Journal 2007;83(985):698-704.

\section{Source of Support: Nil; Conflict of Interest: None}

Submitted: 04-04-2019; Accepted: 10-05-2019; Published online: 15-06-2019 